\title{
ОБЗОР ИССЛЕДОВАНИЙ ПРОГРЕССИИ ФИБРОЗА ПЕЧЁНОЧНОЙ ТКАНИ ПОСЛЕ ТРАНСПЛАНТАЦИИ ПЕЧЕНИ
}

\section{REVIEW OF STUDIES \\ ON THE PROGRESSION \\ OF HEPATIC FIBROSIS \\ AFTER LIVER TRANSPLANTATION}

\section{K. Burtsev}

Summary. Liver fibrosis occurs as a result of an overreaction of wound healing in most chronic liver diseases, such as hepatitis C. Despite significant advances in antiviral therapy in recent years, progressive liver fibrosis remains a serious problem for patients with recurrent hepatitis C after liver transplantation. Liver biopsy remains a central tool in the management of HCV transplant patients, but reliable non-invasive methods for assessing liver fibrosis, such as ultrasound elastography, are increasingly being incorporated into the management of patients after transplantation, helping to predict, make treatment decisions, and stratify patients for new types of antifibrotic therapy.

Keywords: cirrhosis, Fibrosis, HCV, Liver, Transplantation.

\author{
Бурцев Кирилл Юрьевич \\ Aсnирант, ФГАОУ ВО «Российский университет \\ дружбы народов» (РУДН), г. Москва \\ kreshenj@gmail.com
}

Аннотация. Фиброз печени возникает в результате чрезмерной реакции заживления ран при большинстве хронических заболеваний печени, таких как гепатит С. Несмотря на значительные успехи в противовирусной терапии в последние годы, прогрессирующий фиброз печени остается серьезной проблемой для пациентов с рецидивирующим гепатитом С после трансплантации печени. Биопсия печени остается центральным инструментом в ведении пациентов с ВГС-трансплантатом, но надежные неинвазивные методы оценки фиброза печени, такие как ультразвуковая эластография, все чаще включаются в ведение пациентов после трансплантации, помогая прогнозировать, принимать решения о лечении и стратифицировать пациентов для новых видов антифибротической терапии.

Ключевые слова: цирроз, Фиброз, ВГС, Печень, Трансплантация.

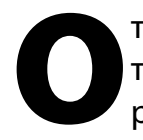
тложение фиброзной ткани в большинстве трансплантированных ВГС печени сильно ускоряется с развитием мостикового фиброза и цирроза у 20-54\% в 5 лет и 32-51\% в 7 лет [18], [8]. Причины для тщательного мониторинга прогрессирования фиброза после трансплантации печени включают:

плохую корреляцию между функциональными тестами печени и гистология, как у реципиентов HCV, так и у реципиентов без HCV [16]; в одном недавнем исследовании, в котором было взято 165 биопсий во время тестов нормальной функции печени, гистологические аномалии были обнаружены почти в одной трети биопсий (11,5\% из которых были признаны клинически значимыми), включая жировую болезнь печени низкой степени / рецидивирующий гепатит С низкой стадии, первичный билиарный цирроз печени или центральный венулит [1];

обычно высокая скорость прогрессирования фиброза при трансплантации по сравнению с пациентами, не перенесшими трансплантацию, со средними годовыми темпами в диапазоне от 0,2 до 0,8 стадий метавира в год [17] по сравнению с 0,1-0,2 у иммунокомпетентных пациентов без трансплантации. Более того, прогрессирование фиброза часто не является линей- ным и может иметь раннее экспоненциальное увеличение, а также позднее начало [4]. Фактически, отсутствие линейности было недавно подтверждено немарковским анализом, основанным на 901 оценке гистологического фиброза у 401 пациента [2]. Более того, эта модель показала, что риск прогрессирования снижался по мере увеличения времени, проведенного на данной стадии фиброза. Однако, более длительное время, необходимое для достижения этой стадии, не предсказывало риск прогрессирования на более высокую стадию. Другими словами, это указывает на то, что активность болезни изменяется во времени и что текущее время на данной стадии, а не предыдущее время на более ранних стадиях, является наиболее предсказуемым для будущего прогрессирования [2];

возможность предсказать результат. Действительно, ход прогрессирования, по-видимому, определяется на ранней стадии после трансплантации, а стадия фиброза в течение первого года, как было показано, тесно связана с последующим прогрессированием до цирроза, а также с выживаемостью трансплантата и пациента. Дополнительная информация, которая может быть использована для прогнозирования риска прогрессирования фиброза, включает степень некровоспаления при ранних биопсиях, возраст донора, вирусную на- 
грузку, степень иммуносупрессии, а также сопутствующие осложнения, возникающие в течение первых месяцев после трансплантации, в основном желчные осложнения. В частности, степень некровоспаления помогает выявить лиц с повышенным риском прогрессирования фиброза и с нарушенной выживаемостью [11]. В целом, пациенты с хотя бы умеренным фиброзом (Metavir F $\geq 2$ ) на первом году жизни имеют значительно больший риск развития цирроза и более низкую выживаемость трансплантата и пациентов, чем пациенты с минимальным или отсутствующим фиброзом;

ограниченная эффективность, но высокая токсичность противовирусных препаратов у реципиентов трансплантата [9], [3]. Различие между пациентами с медленным и быстрым прогрессированием фиброза позволит избежать ненужной противовирусной терапии у пациентов с ожидаемой хорошей долгосрочной выживаемостью, в то же время, требуя раннего лечения у пациентов с высоким риском прогрессирования заболевания;

повышение эффективности и снижение токсичности, если противовирусная терапия начинается на менее поздних стадиях фиброза, особенно до развития цирроза [3]. Примером этого является исследование одного центра, в котором более низкие показатели устойчивого вирусного ответа (УВО) были достигнуты у реципиентов, получавших лечение в более поздний период времени (2001-2005 гг.: $n=71,42 \%$ по сравнению с 2006-2007 гг.: $n=36 ., 24 \% ; ~ p=0,043)$. Одним из вероятных объяснений является большая доля пациентов, получающих лечение на поздних стадиях, что связано с более низкими показателями выведения вируса. В частности, из 22 пациентов с исходным циррозом печени только 4 (18\%) достигли УВО, тогда как 34 из 83 (41\%) пациентов без цирроза печени достигли УВО [3]. Повышенная частота УВО (с 25\% до 54\%) была позже достигнута в том же центре после того, как политика лечения была изменена, чтобы начать терапию на более низких стадиях фиброза (количество пациентов с циррозом снизилось с 20,5\% до 7\%) в сочетании с более высокими дозами рибавирина [3]. Другие показали, что среди 113 пациентов с частотой УВО 38\% переносимость терапии значительно снизилась у пациентов со стадией фиброза $\geq 3$ при исходной биопсии печени. В общей сложности 20\% пациентов на поздней стадии умерли или были повторно трансплантированы из-за печеночной недостаточности по сравнению с $1 \%$ пациентов со стадией фиброза <3 [13]. Пока неясно, сохранится ли то же самое в эпоху новых пероральных противовирусных препаратов прямого действия;

потенциальное сосуществование других поражений, некоторые из которых следует исключить до на- чала противовирусной терапии с интерфероновыми режимами, такими как отторжение или аутоиммунитет [9]. В недавнем исследовании аутоиммунные признаки (в основном плазматический гепатит) в биоптатах печени, собранных перед терапией пег-интерфероном, были одним из основных факторов риска развития связанной с интерфероном тяжелой иммуноопосредованной дисфункции трансплантата, характеризующейся явным гепатитом или отторжением плазматических клеток. [9].

Чтобы контролировать прогрессирование фиброза, большинство консенсусных конференций настоятельно рекомендуют выполнение протокольных биопсий печени через различные промежутки времени, практика, которая широко принята многими, хотя и не всеми бригадами трансплантологов. Идеальный интервал между биопсиями не установлен, но, учитывая сжатый естественный анамнез рецидива гепатита $C$, некоторые авторы рекомендуют ежегодные интервалы. Используются несколько гистологических баллов без доказательства превосходства одной из них. Добавление измерения HVPG может повысить точность диагностики, в частности, выявлять пациентов с высоким риском декомпенсации функции печени. В одном исследовании HVPG $\geq 6$ мм рт.ст. через 1 год после трансплантации идентифицировали 12 (80\%) из 15 пациентов с тяжелым рецидивом, тогда как только у девяти (60\%) из них был значительный фиброз (F $\geq 2$ ) в течение первого года биопсии [5]. Во втором исследовании у 4 из 13 (31\%) реципиентов с портальной гипертензией (HVPG $\geq 6$ мм рт. Ст.) Наблюдалась декомпенсация, по сравнению с никем из 29 пациентов без портальной гипертензии [15]. Тесная корреляция между стадией фиброза и HVPG была описана в обоих исследованиях, а противоречивые результаты в основном были связаны с вариабельностью образцов биопсии и конкретными гистологическими особенностями, такими как перисинусоидальный фиброз, а не с ошибками при измерении HVPG.

Несмотря на свою неоспоримую ценность, биопсия имеет ограничения в популяции трансплантатов печени, что широко продемонстрировано на пациентах, не перенесших трансплантацию. Это инвазивный инструмент с небольшим, но, тем не менее, существующим риском заболеваемости и смертности, и не всегда приемлем для реципиентов трансплантата. Расчетная частота серьезных осложнений составляет 0,6\%, а уровень смертности - 0,02\%. Кроме того, ошибки в определении стадии фиброза возникают в результате вариабельности выборки, особенно при биопсии иглой недостаточной длины. Наконец, отсутствие опыта интерпретации биопсии трансплантата может привести к неправильной оценке стадии фиброза [14]. 
Специфическая антифибротическая терапия потребуется пациентам, которые не избавляются от вируса и / или имеют дополнительные факторы риска прогрессирования фиброза. На протяжении многих лет клиническая разработка антифибротической терапии застопорилась, в основном из-за отсутствия (1) подходящих мишеней, (2) антифибротических агентов с высокой специфичностью и приемлемым профилем побочных эффектов и (3) чувствительных и специфических биомаркеров или технологии визуализации, отражающие фиброз печени и особенно фиброгенез. Таким образом, только 4 основных исследования были выполнены при ХГС, с подтвержденным биопсией прогрессированием фиброза в качестве первичной конечной точки, тестированием IL-10, интерферона- $\gamma$, глитазона и интерферона-а., все они с неутешительными результатами [10], подчеркивая необходимость оптимизированного доклинического тестирования перед переводом в клинику [12]. Тем не менее, эта область набирает обороты после увеличения числа многообещающих мишеней и лекарств в результате высококачественных доклинических исследований, продолжающейся разработки и проверки улучшенных биомаркеров и методов визуализации фиброза и фиброгенеза, а также растущего интереса малых и крупных фармацевтических компаний на потенциально обширном рынке антифибротиков [6], [7].

\section{ЛИТЕРАТУРА}

1. Abraham S.C. et al. Histologic abnormalities are common in protocol liver allograft biopsies from patients with normal liver function tests //The American journal of surgical pathology.— 2008.—- T. 32.— № .7.- C. 965-973.

2. Bacchetti P. et al. Non-Markov multistate modeling using time-varying covariates, with application to progression of liver fibrosis due to hepatitis C following liver transplant //The international journal of biostatistics. - 2010.- T. 6. — № . 1.

3. Berenguer M. et al. Comparison of two non-contemporaneous HCV-liver transplant cohorts: strategies to improve the efficacy of antiviral therapy //Journal of hepatology. - 2012. - T. 56. — №.6.-C. 1310-1316.

4. Berenguer M. et al. Delayed onset of severe hepatitis C - Related liver damage following liver transplantation: A matter of concern? //Liver transplantation. 2003. 一 T. 9. — № . 11.—C. 1152-1158.

5. Blasco A. et al. Hepatic venous pressure gradient identifies patients at risk of severe hepatitis C recurrence after liver transplantation //Hepatology. - 2006.T. 43.— № . 3.—C. 492-499.

6. Di Bisceglie A.M. et al. Prolonged therapy of advanced chronic hepatitis ( with low-dose peginterferon //New England Journal of Medicine. - 2008. T. 359. - № . 23. - C. 2429-2441.

7. Guha I.N. et al. Biomarkers of liver fibrosis: what lies beneath the receiver operating characteristic curve? //Hepatology. — 2011.— T. 54.— № . 4. C. 1454-1462.

8. Lai J.C. et al. Hepatitis C virus-infected women have a higher risk of advanced fibrosis and graft loss after liver transplantation than men //Hepatology.2011.— - T. 54. — № . 2.—C. 418-424.

9. Levitsky J. et al. Risk for immune-mediated graft dysfunction in liver transplant recipients with recurrent HCV infection treated with pegylated interferon // Gastroenterology. - 2012.- - . 142.— №.5.-C. 1132-1139. e1.

10. McHutchison J. et al. Farglitazar lacks antifibrotic activity in patients with chronic hepatitis C infection //Gastroenterology. — 2010. — T. 138. — № . 4.— C. 1365-1373. e2.

11. Meriden Z. et al. Histologic predictors of fibrosis progression in liver allografts in patients with hepatitis C virus infection //Clinical gastroenterology and hepatology.—2010.-T. 8. - № .3.-C. 289-296. e8.

12. Popov Y., Schuppan D. Targeting liver fibrosis: strategies for development and validation of antifibrotic therapies //Hepatology. — 2009.— T. 50.— № . 4.— C. 1294-1306.

13. Roche B. et al. Hepatitis C virus therapy in liver transplant recipients: response predictors, effect on fibrosis progression, and importance of the initial stage of fibrosis //Liver transplantation. - 2008. - T. 14. - № . 12.-C. 1766-1777.

14. Rockey D.C. et al. Liver biopsy //Hepatology. — 2009.—T. 49. — № . 3. - C. 1017-1044.

15. Samonakis D.N. et al. Hepatic venous pressure gradient to assess fibrosis and its progression after liver transplantation for HCV cirrhosis //Liver Transplantation. 2007.— T. 13.—№ . 9.—C. 1305-1311.

16. Sebagh M. et al. Twenty-year protocol liver biopsies: Invasive but useful for the management of liver recipients //Journal of hepatology. — 2012. - T. 56.— № . 4.- - C. 840-847.

17. Selzner N. et al. The difference in the fibrosis progression of recurrent hepatitis C after live donor liver transplantation versus deceased donor liver transplantation is attributable to the difference in donor age //Liver Transplantation. - 2008. - T. 14. — № . 12. - C. 1778-1786.

18. Yilmaz N. et al. A prospective evaluation of fibrosis progression in patients with recurrent hepatitis C virus following liver transplantation //Liver Transplantation. - 2007.— T. 13.— № .7.—C. 975-983. 